\title{
On the firm's option values of short-time work policies
}

\author{
Kuno J. M. Huisman ${ }^{1,2} \cdot$ Jacco J. J. Thijssen ${ }^{3,4}$ (D) \\ Received: 5 March 2019 / Accepted: 8 January 2020 / Published online: 18 January 2020 \\ (c) The Author(s) 2020
}

\begin{abstract}
We analyse the short-time work (STW) regulations that several OECD countries introduced after the 2007 financial crisis. We view these measures as a collection of real options and study the dynamic effect of STW on the endogenous liquidation decision of the firm. While STW delays a firm's liquidation, it is not necessarily welfare enhancing. Moreover, it turns out that firms use STW too long. We show (numerically) that providers of capital benefit more than employees from STW. Benefits for employees can even be negative. A typical Nordic policy performs better than a typical Anglo-Saxon policy for all stakeholders.
\end{abstract}

Keywords Temporary unemployment $\cdot$ Real options $\cdot$ Dynamic cost-benefit analysis

JEL Classification G33 • G38 · H53

\section{Introduction}

Many commonly-used economic policies have welfare effects that depend crucially on economic agents' timing decisions. As an example take short-time work (STW) arrangements, which are used to reduce the number of lay-offs in economically challenging times by temporarily allowing employers to reduce the hours worked by their employees. Even though there are many differences in the precise rules governing STW in different countries (such as eligibility criteria, duration, etc.) the basic idea is similar: rather than laying off workers,

We thank Peter Kort, as well as seminar participants at the 15th Annual International Conference on Real Options in Turku, Finland, the University of York, Hull University Business School, and the INFORMS Annual Meeting in San Francisco for helpful comments. We gratefully acknowledge the helpful comments received from the Editor (Riedel) and two anonymous referees. All errors are ours.

$\bowtie \quad$ Jacco J. J. Thijssen

jacco.thijssen@york.ac.uk

1 CentER, Department of Econometrics and Operations Research, Tilburg University, Post Office Box 90153, 5000 LE Tilburg, The Netherlands

2 ASML Netherlands B.V., Post Office Box 324, 5500 AH Veldhoven, The Netherlands

3 The York Management School, University of York, Heslington, York YO10 5GD, UK

4 Department of Mathematics, University of York, Heslington, York YO10 5DD, UK 
firms are allowed to put employees on reduced hours. Affected workers are compensated for the resulting loss in wage income, partly by employers and partly by the government. ${ }^{1}$

In order to make a full welfare analysis of an STW policy one needs to know by how much both the costs to the government and the benefits to the workers should be discounted. Both these discount factors depend on the timing decisions of the firm: when (if ever) it enters STW, when (if ever) it exists, when (if ever) it liquidates. These decisions, in turn, will depend on the underlying, uncertain, state of the economy as relevant to the firm. The discounted costs and benefits of STW will, thus, depend on firms' timing decisions under future uncertainty. To facilitate the analysis of STW it helps to view it as providing the firm with a collection of real options. First it has an option to enter STW. Once this option is exercised it has an option to either liquidate or leave STW. If the firm exits STW it again has an option to liquidate. This concatenation of options makes valuing STW measures in general a difficult problem, especially in a general equilibrium framework. Therefore, in this paper we focus on the value of STW to the firm and its constituents: its shareholders, employees, and providers of capital.

This paper analyses three issues related to STW that have been addressed to some extent in the literature, but will be studied here in a dynamic stochastic framework that focusses on the incentives it creates for employers. First, it has been argued [2] that, while from the employee's point of view STW is preferable to lay-offs, they are close substitutes for employers. However, since laying off staff is an (at least partly) irreversible decision, while STW is not, the option of STW has economic value to the firm.

A second, related, issue is the concern that STW can lead to inefficient reductions in working hours (cf. [19]) for which some empirical evidence has been found [7]. We find a theoretical reason for this inefficiency, linked to the option value that STW presents. Most countries have provisions that preclude firms from signing up to STW if and when they like. This adds a degree of irreversibility to the decision to leave STW once a firm is using it. This irreversibility, in turn, creates an option value of waiting, which gives the firm a disincentive to return employees to full hours. This effect is driven purely by irreversibility and uncertainty over the firm's prospects and affects even risk-neutral firms.

A third question is related to who benefits most from STW. We analyse a typical situation where the firm's production technology is of the Cobb-Douglas type with two inputs: capital and labour. In that set-up, labour is "rented" from labourers and capital goods are rented from providers of capital goods, who we shall refer to here as "capitalists". Shareholders claim the firm's profits. It is assumed that managers maximize shareholder value, that there are no agency issues, and that the firm is $100 \%$ equity-financed. So, although we can think of workers and capitalists as stakeholders in the firm, we view them as outsiders who have no agency in the firm's decision making. In particular, the capitalists are not the providers of (financial) capital; rather, they are providers of the capital goods that the firm rents for its production process.

STW is usually introduced by appealing to the advantages that it has for workers. Indeed, STW delays or prevents workers from being laid-off and, hence, reduces the present value of the sunk-costs of being made redundant, estimated to be some $11 \%$ of life-time earnings [8]. However, STW is also beneficial to the providers of the firm's capital goods ("capitalists") and shareholders. Capitalists benefit, because they get fully paid for the capital stock throughout the STW period. Shareholders benefit, because STW gives them additional options in managing the firm, which have a positive value. So, from the firm's perspective STW and

1 In 2011, STW measures were in place in 25 of 33 OECD countries with take-up rates being as high as $7.4 \%$ of employees in some countries in 2009 [7]. It has been estimated, for example, that STW has saved 5000-6000 jobs in the Netherlands alone [13]. 
liquidation are not close substitutes. This is because liquidation is irreversible, while using STW is not. So, STW gives the firm additional flexibility to deal with unfavourable economic circumstances, which has economic value for the firm.

We perform a numerical analysis of our model to study its features in more detail. This analysis is based on two examples of typical STW policies, that we call the "Anglo-Saxon" and the "Nordic" policy. These proto-typical policies are averages of policies as have been documented in the literature (see [7]) of some Anglo-Saxon and Nordic countries, respectively. The main difference between these policies is that the Nordic countries, typically, allow firms to cut into normal production levels more deeply, while permitting lower salary reductions.

From this numerical analysis we find that, from a social welfare perspective, firms use STW too long. This is related to the option value of STW: leaving STW is an irreversible decision. This irreversibility gives the firm an option to use STW longer than it otherwise would. These two effects may also give a different explanation to the observed lag between macro variables and labour adjustment as analysed by van Wijnbergen and Willems [21]. Secondly, we find that, on the whole, the providers of capital goods benefit more from STW than providers of labour. In addition, all interested parties (providers of capital goods and labour services, as well as shareholders) are better off in a typical Nordic programme than in a typical AngloSaxon programme. Finally, in all cases, the benefit-to-cost ratio is significantly below unity, indicating the importance of a stochastic dynamic approach to analysing measures like STW. In general we find that the benefits and costs of STW measures are very sensitive to the policy's parameters and that no clear policy prescriptions emerge. This point is also made in some recent empirical work on STW measures by Boeri and Bruecker [6].

The paper uses a real options approach to the analysis of unemployment insurance by focussing on the effects of irreversibility and uncertainty on the value of STW measures to the firm. The use of real options analysis is well-established in the analysis of economic decision making. Since the seminal contributions of McDonald and Siegel [16] and Dixit and Pindyck [10] there has been a burgeoning literature on applications of the real options approach. For example, Abel and Eberly [1] and Dixit [9] use the framework to analyse optimal investment in the production factors in a firm, Bar-Ilan and Strange [3] use it to investigate the consequences of construction lags on optimal investment decision. In a recent contribution, Kellogg [14] gives evidence that the decision rules that theoretic real options models prescribe are consistent with actual firm behaviour.

Not much theoretical work has been conducted in the use of STW to dampen the effects of the recent recession. Some contributions, like Bentolila et al. [4] focus on labour market flexibility, in particular the use of temporary workers, as an explanation for the different effects of the recession in different labour markets. To our knowledge, our paper is the first that applies a real options framework to STW. In general, there are few contributions that focus on the optionality that labour-market policies confers on employers. In fact, most contributions abstract away from this and focus on issues such as moral hazard; see, e.g. Blanchard and Tirole [5] who focus on the effect of unemployment insurance and protection on optimal wage contracts between employer and worker, and Kolsrud et al. [15], who focus on optimal timing of (un-) employment by workers.

In this paper, we choose not to model the workers' side of the labour market at all. There are concerns that STW unduly advantages workers employed in firms that can use STW, although there is no conclusive evidence that this really takes place [7]. In addition, it can be argued that during times of economic hardship, which STW measures are designed to alleviate, the labour market will not be very "liquid", making it difficult for workers to switch jobs. 
Finally, a focus on the firm allows for analytical solutions and a clear understanding how irreversibility and uncertainty drive the value of STW.

The paper is organized as follows. In Sect. 2 we set up the model and derive the firm's optimal policy by valuing three subsequent (real) options implied by a (stylized) model of STW. The effects of STW on liquidation probabilities and welfare are analysed in Sects. 3 and 4 , respectively. Some concluding remarks are given in Sect. 5.

\section{Optimal use of short-time work by firms}

As mentioned in Sect. 1, the details of STW measures vary substantially across countries, although the main idea is the same: employers can put staff on reduced hours, while the government partially compensates for lost wage earnings. In this section we will study the effect of STW on the firm's liquidation decision. The main idea of our model is that STW provides the firm with an option to postpone an irreversible liquidation decision by lowering its production level, which reduces its (stochastic) revenues as well as its (deterministic) costs. This generates a trade-off for the firm where STW is attractive when its sales price is low, but not when it is high; an assumption that we will formalize below (cf. Assumption 1). As far as the details of the STW measure, we make the following additional simplifying assumptions. First the firm can use STW only once, second the option to use STW is infinitely lived, third the use of STW does not involve sunk costs and fourth the firm can decide itself when to stop STW.

The second and third assumptions are, arguably, the most unrealistic ones. Both are made for technical convenience and can be relaxed. However, when options are not infinitely lived no analytical results can be obtained, although it has been shown that even for moderate finite life times the (numerically obtained) solutions are very similar to those obtained analytically under an infinite time horizon [11]. The assumption that the use of STW does not involve sunk costs implies that a firm will use STW sooner than in the case that sunk costs are present. The result that sunk costs delay investment is standard in the literature ${ }^{2}$ and the same intuition applies here as well.

Our assumptions imply that the firm has three subsequent options. First the option to enter STW. Second, once entered, the firm has the options to (i) exit STW and return to normal production, or (ii) to liquidate. Third, if the firm decided to exit STW and return to normal production, then it now has an option to liquidate. Since our stochastic process will be strongly Markovian, we can value these three options successively, starting with the final one.

\subsection{The value of an active firm that has already used STW}

In this section we analyse the value of a firm that is currently active in a market and has already used STW. Such a firm no longer has an option to enter STW and we will assume that the only option that is left to the firm is to liquidate at a time of its choosing. Liquidation implies laying off all workers and retiring all capital stock. We make the following two simplifying assumptions. First, upon liquidation the firm does not receive a scrap value for its capital stock and, second, liquidation does not involve sunk costs.

The crucial ingredient in our model is that the evolution of the firm's revenues is subject to uncertainty. Uncertainty is modeled on a measurable space $(\Omega, \mathscr{F})$. We consider a family

${ }^{2}$ See, for example, [10, Chapter 6]. 
of probability measures $\mathrm{P}_{y}, y \in \mathbb{R}_{+}$, on $(\Omega, \mathscr{F})$. A particular firm is assumed to have a cash inflow that is given by $Q_{N} Y$, where $Q_{N}$ is the production level of the firm and $Y$ is the stochastically evolving price level, which under $\mathrm{P}_{y}$, evolves according to the geometric Brownian motion (GBM),

$$
d Y_{t}=\mu Y_{t} d t+\sigma Y_{t} d z_{t}, \quad Y_{0}=y, \mathrm{P}_{y} \text {-a.s. }
$$

where $\left(z_{t}\right)_{t \geq 0}$ is a Wiener process. Information is modeled by the filtration generated by this GBM, augmented with the $\mathrm{P}_{y}$-null sets, and is denoted by $\left(\mathscr{F}_{t}\right)_{t \geq 0}$.

It is assumed that under normal conditions the firm produces a quantity $Q_{N}$ at a $\cos c_{N}$, and that it discounts profits at a constant rate $r>\mu .^{3}$

The present value (under $\mathrm{P}_{y}$ ) of an operational firm without the liquidation option is

$$
F_{N}(y)=\mathrm{E}_{y}\left[\int_{0}^{\infty} e^{-r t}\left(Q_{N} Y_{t}-c_{N}\right) d t\right]=\frac{Q_{N} y}{r-\mu}-\frac{c_{N}}{r} .
$$

The firm's value with the liquidation option is the solution to the optimal stopping problem

$$
\begin{aligned}
F_{N}^{*}(y) & =\sup _{\tau \in \mathscr{M}} \mathrm{E}_{y}\left[\int_{0}^{\tau} e^{-r t}\left(Q_{N} Y_{t}-c_{N}\right) d t\right] \\
& =F_{N}(y)+\sup _{\tau \in \mathscr{M}} \mathrm{E}_{y}\left[e^{-r \tau}\left(-F_{N}\left(Y_{\tau}\right)\right)\right],
\end{aligned}
$$

where $\mathscr{M}$ is the set of stopping times relative to the filtration $\left(\mathscr{F}_{t}\right)_{t \geq 0}$.

The optimal stopping problem (1) is standard and can easily be solved; see, for example [17, Exercise 10.12]. It turns out that the optimal liquidation time is the first hitting time (from above) of an endogenously determined threshold of the stochastic process $Y$, which we shall denote by $Y_{N}^{*}$. As this result is standard, it will be summarized in a proposition without proof. The interested reader is referred to Dixit and Pindyck [10], Stokey [20], or $\varnothing$ ksendal [17] for proofs. In the remainder, let $\check{\tau}\left(Y_{N}^{*}\right):=\inf \left\{t \geq 0 \mid Y_{t} \leq Y_{N}^{*}\right\}$ denote the first hitting time (from above) of the trigger $Y_{N}^{*}$.

Proposition 1 The stopping time $\check{\tau}\left(Y_{N}^{*}\right)$, with

$$
Y_{N}^{*}=\frac{\beta_{2}}{\beta_{2}-1} \frac{r-\mu}{Q_{N}} \frac{c_{N}}{r},
$$

where $\beta_{2}<0$ is the negative root of the quadratic equation

$$
\frac{1}{2} \sigma^{2} \beta(\beta-1)+\mu \beta-r=0,
$$

solves the optimal stopping problem (1). Moreover, the corresponding value function is

$$
F_{N}^{*}(y)= \begin{cases}\frac{Q_{N} y}{r-\mu}-\frac{c_{N}}{r}+\left(\frac{y}{Y_{N}^{*}}\right)^{\beta_{2}}\left[\frac{c_{N}}{r}-\frac{Q_{N} Y_{N}^{*}}{r-\mu}\right] & \text { if } y>Y_{N}^{*}, \\ 0 & \text { if } y \leq Y_{N}^{*} .\end{cases}
$$

Note that the value function $F_{N}^{*}$ is $C^{1}$ on $\mathbb{R}_{+}$and $C^{2}$ on $\mathbb{R}_{+} \backslash\left\{Y_{N}^{*}\right\}$.

The value function in (3) has a straightforward interpretation. For $y \leq Y_{N}^{*}$, the firm liquidates immediately and its value is, thus, zero. For $y>Y_{N}^{*}$ the firm's value consists of the expected present value of always producing $Q_{N}$ at $\operatorname{cost} c_{N}$, corrected for the fact that at some point in the future the threshold $Y_{N}^{*}$ may be reached. The expected discount factor of this event is $\left(y / Y_{N}^{*}\right)^{\beta_{2}}$.

3 This assumption ensures that the present value of profits is finite in our infinite horizon model. 


\subsection{The value of a firm currently using STW}

Once the firm has decided to enter STW it has two, inter-related options:

1. leave STW and return to normal production;

2. leave STW and liquidate.

This problem has two aspects: (i) the optimal decision time has to be determined and (ii) the optimal decision at that time has to be determined. Of course, STW only makes sense if it allows firms to reduce costs by lowering the wage bill through reduced hours for its workers. Therefore, the per-period costs during STW are assumed to be constant and equal to $c_{P} \in$ $\left(0, c_{N}\right)$. The quid pro quo is that the firm will produce less than before, say $Q_{P} \in\left(0, Q_{N}\right)$. We will assume that, on average, normal production is more profitable than production in STW.

Assumption 1 The production and cost levels in STW, $Q_{P}$ and $c_{P}$, are such that $Q_{N} / c_{N}>$ $Q_{P} / c_{P}$.

Essentially this assumption says that $Q_{N}$ is a more efficient production level than $Q_{P}$. If it is violated then the firm may never wish to leave STW once it has entered.

The value of an active firm using STW with the two exit options described above, can now be written as the optimal stopping problem

$$
\begin{aligned}
F_{P}^{*}(y) & =\sup _{\tau \in \mathscr{M}} \mathrm{E}_{y}\left[\int_{0}^{\tau} e^{-r t}\left(Q_{P} Y_{t}-c_{P}\right) d t+e^{-r \tau} \max \left\{F_{N}^{*}\left(Y_{\tau}\right), 0\right\}\right] \\
& =\sup _{\tau \in \mathscr{M}} \mathrm{E}_{y}\left[\int_{0}^{\tau} e^{-r t}\left(Q_{P} Y_{t}-c_{P}\right) d t+e^{-r \tau} F_{N}^{*}\left(Y_{\tau}\right)\right] .
\end{aligned}
$$

Note that the gain function is $C^{1}$ everywhere, so that problem (4) is fairly standard. We hypothesize that the state space can be split up in a continuation region $\left(0, Y_{L}^{*}\right) \cup\left(Y_{H}^{*}, \infty\right)$ and a stopping region $\left[Y_{L}^{*}, Y_{H}^{*}\right]$. So, the optimal stopping time, $\tau_{L, H}^{*}$ would be

$$
\tau_{L, H}^{*}=\hat{\tau}\left(Y_{H}^{*}\right) \wedge \check{\tau}\left(Y_{L}^{*}\right),
$$

where $\hat{\tau}\left(Y_{H}^{*}\right):=\inf \left\{t \geq 0 \mid Y_{t} \geq Y_{H}^{*}\right\}$. This intuition will be verified in Proposition 2 below. The resulting value function turns out to be $C^{1}$ everywhere and $C^{2}$ on $\mathbb{R}_{+} \backslash\left\{Y_{L}^{*}, Y_{H}^{*}\right\}$.

An STW policy only makes sense if a firm that uses STW liquidates later than a firm that does not. It will be seen later that the following assumption ensures that $Y_{L}^{*}<Y_{N}^{*}$.

Assumption 2 For the unique solution $\hat{Y}_{H}>Y_{N}^{*}$ to the equation

$$
\begin{gathered}
\frac{\beta_{1} \beta_{2}}{\beta_{1}-\beta_{2}}\left(\frac{Q_{P} Y_{N}^{*}}{r-\mu}-\frac{c_{P}}{r}\right)\left[\left(\frac{\hat{Y}_{H}}{Y_{N}^{*}}\right)^{\beta_{1}}-\left(\frac{\hat{Y}_{H}}{Y_{N}^{*}}\right)^{\beta_{2}}\right] \\
-\frac{Q_{P} Y_{N}^{*} /(r-\mu)}{\beta_{1}-\beta_{2}}\left[\beta_{1}\left(\frac{\hat{Y}_{H}}{Y_{N}^{*}}\right)^{\beta_{1}}-\beta_{2}\left(\frac{\hat{Y}_{H}}{Y_{N}^{*}}\right)^{\beta_{2}}\right] \\
=\frac{Q_{N}-Q_{P}}{r-\mu} \hat{Y}_{H}+\beta_{2}\left(\frac{\hat{Y}_{H}}{Y_{N}^{*}}\right)^{\beta_{2}}\left[\frac{c_{N}}{r}-\frac{Q_{N} Y_{N}^{*}}{r-\mu}\right],
\end{gathered}
$$

it holds that

$$
\frac{\left(\beta_{2}-1\right) Q_{p} Y_{N}^{*} /(r-\mu)-\beta_{2} c_{P} / r}{\beta_{1}-\beta_{2}}\left(\frac{\hat{Y}_{H}}{Y_{N}^{*}}\right)^{\beta_{1}}+\frac{\left(1-\beta_{1}\right) Q_{p} Y_{N}^{*} /(r-\mu)+\beta_{1} c_{P} / r}{\beta_{1}-\beta_{2}}\left(\frac{\hat{Y}_{H}}{Y_{N}^{*}}\right)^{\beta_{2}}
$$




$$
<\frac{Q_{N}-Q_{P}}{r-\mu} \hat{Y}_{H}+\left(\frac{\hat{Y}_{H}}{Y_{N}^{*}}\right)^{\beta_{2}}\left[\frac{c_{N}}{r}-\frac{Q_{N} Y_{N}^{*}}{r-\mu}\right] .
$$

Denote the expected value (under $\mathrm{P}_{y}$ ) of operating in STW forever by $F_{P}(y)$, i.e.,

$$
F_{P}(y)=\mathrm{E}_{y}\left[\int_{0}^{\infty} e^{-r t}\left(Y_{t} Q_{P}-c P\right) d t\right]=\frac{Q_{P} y}{r-\mu}-\frac{c_{P}}{r} .
$$

Proposition 2 If Assumptions 1 and 2 are satisfied, then there is a unique pair $\left(Y_{L}^{*}, Y_{H}^{*}\right)$, with $Y_{L}^{*}<Y_{N}^{*}<Y_{H}^{*}$, such that the stopping time $\tau_{L, H}^{*}$ in (5) solves the optimal stopping problem (4). The triggers $Y_{L}^{*}$ and $Y_{H}^{*}$ are uniquely determined by the equations

$$
\begin{aligned}
& \frac{\left(\beta_{2}-1\right) Q_{P} Y_{L}^{*} /(r-\mu)-\beta_{2} c_{P} / r}{\left(\beta_{1}-\beta_{2}\right)\left(Y_{L}^{*}\right)^{\beta_{1}}}\left(Y_{H}^{*}\right)^{\beta_{1}}+\frac{\left(1-\beta_{1}\right) Q_{P} Y_{L}^{*} /(r-\mu)+\beta_{1} c_{P} / r}{\left(\beta_{1}-\beta_{2}\right)\left(Y_{L}^{*}\right)^{\beta_{2}}}\left(Y_{H}^{*}\right)^{\beta_{2}} \\
& \quad=F_{N}^{*}\left(Y_{H}^{*}\right)-F_{P}\left(Y_{H}^{*}\right) \\
& \beta_{1} \frac{\left(\beta_{2}-1\right) Q_{P} Y_{L}^{*} /(r-\mu)-\beta_{2} c_{P} / r}{\left(\beta_{1}-\beta_{2}\right)\left(Y_{L}^{*}\right)^{\beta_{1}}}\left(Y_{H}^{*}\right)^{\beta_{1}-1} \\
& \quad+\beta_{2} \frac{\left(1-\beta_{1}\right) Q_{P} Y_{L}^{*} /(r-\mu)+\beta_{1} c_{P} / r}{\left(\beta_{1}-\beta_{2}\right)\left(Y_{L}^{*}\right)^{\beta_{2}}}\left(Y_{H}^{*}\right)^{\beta_{2}-1} \\
& =\frac{\partial F_{N}^{*}\left(Y_{H}^{*}\right)}{\partial y}-\frac{\partial F_{P}\left(Y_{H}^{*}\right)}{\partial y}
\end{aligned}
$$

Furthermore, the value function is

$$
F_{P}^{*}(y)= \begin{cases}0 & \text { if } y \leq Y_{L}^{*} \\ F_{P}(y)+\frac{\left(Y_{H}^{*}\right)^{\beta_{1}} y^{\beta_{2}}-y^{\beta_{1}}\left(Y_{H}^{*}\right)^{\beta_{2}}}{\left(Y_{H}^{*}\right)^{\beta_{1}}\left(Y_{L}^{*}\right)^{\beta_{2}}-\left(Y_{L}^{*}\right)^{\beta_{1}}\left(Y_{H}^{*}\right)^{\beta_{2}}}\left[-F_{P}\left(Y_{L}^{*}\right)\right] & \\ \quad+\frac{y^{\beta_{1}}\left(Y_{L}^{*}\right)^{\beta_{2}}-\left(Y_{L}^{*}\right)^{\beta_{1}} y^{\beta_{2}}}{\left(Y_{H}^{*}\right)^{\beta_{1}}\left(Y_{L}^{*}\right)^{\beta_{2}}-\left(Y_{L}^{*}\right)^{\beta_{1}}\left(Y_{H}^{*}\right)^{\beta_{2}}}\left[F_{N}^{*}\left(Y_{H}^{*}\right)-F_{P}\left(Y_{H}^{*}\right)\right] & \text { if } Y_{L}^{*}<y<Y_{H}^{*} \\ F_{N}^{*}(y) & \text { if } y \geq Y_{H}^{*} .\end{cases}
$$

The proof of this proposition can be found in "Appendix A". Note that it is always beneficial to liquidate later under STW than without STW, because $Y_{L}^{*}<Y_{N}^{*}$

This value function again has an appealing intuitive interpretation. The payoffs for $y \leq Y_{L}^{*}$ and $y \geq Y_{H}^{*}$ are the payoffs of immediate liquidation and producing at the normal level (including the option value of liquidation), respectively. The value of the firm in the region $\left(Y_{L}^{*}, Y_{H}^{*}\right)$ consists of three parts. The first part is the expected present value of never leaving STW. The second part is the correction for liquidation at $Y_{L}^{*}$, multiplied by the expected discount factor conditional on reaching $Y_{L}^{*}$ before $Y_{H}^{*}$. The final part is the correction for returning to normal production at $Y_{H}^{*}$, multiplied by the expected discount factor conditional on reaching $Y_{H}^{*}$ before $Y_{L}^{*}$.

\subsection{The value of an active firm that has not yet used STW}

An active firm that has not used STW yet is confronted with the problem of finding the optimal time at which to exchange the expected present value of current production for 
the value of a firm that is using STW, $F_{P}^{*}$. That is, the firm solves the optimal stopping problem

$$
F^{*}(y)=\sup _{\tau \in \mathscr{M}} \mathrm{E}_{y}\left[\int_{0}^{\tau} e^{-r t}\left(Q_{N} Y_{t}-c_{N}\right) d t+e^{-r \tau} F_{P}^{*}\left(Y_{\tau}\right)\right]
$$

Note that the gain function is $C^{1}$ and monotonically increasing, so that we should expect the value function $F^{*}$ to be well-behaved. Intuitively, this problem should, again, have a solution that takes the form of a trigger: enter STW as soon as the process $\left(Y_{t}\right)_{t \geq 0}$ reaches some threshold $Y^{*}$ from above.

In order to prove the existence of such a trigger we need to make an additional assumption that ensures that the expected revenue of STW is sufficiently large. In particular, there must exist states of the economy (i.e. prices $y$ ) for which the expected present value of STW relative to normal operation fall sufficiently short of the expected present value of the cost benefits.

Assumption 3 The expected revenue of STW is sufficiently large, in the sense that

$$
\check{Y} \frac{Q_{N}-Q_{P}}{r-\mu}>\frac{\beta_{1} \beta_{2}}{\left(\beta_{1}-1\right)\left(\beta_{2}-1\right)} \frac{c_{N}-c_{P}}{r},
$$

where

$$
\check{Y}=\left[\frac{1-\beta_{2}}{\beta_{1}\left(\beta_{1}-\beta_{2}\right) \hat{A}} \frac{Q_{N}-Q_{P}}{r-\mu}\right]^{\frac{1}{\beta_{1}-1}},
$$

and $\hat{A}$ is as determined by (8) in Proposition 2.

Proposition 3 Suppose that Assumptions 1-3 hold. Then, in addition to the unique triggers $Y_{L}^{*}$ and $Y_{H}^{*}$, there exists a unique trigger $Y^{*}<Y_{H}^{*}$ such that the stopping time $\check{\tau}\left(Y^{*}\right)$ solves the optimal stopping problem (10). Moreover, the corresponding value function is

$$
F^{*}(y)= \begin{cases}F_{P}^{*}(y) & \text { if } y \leq Y^{*} \\ \frac{Q_{N} y}{r-\mu}-\frac{c_{N}}{r}+\left(\frac{y}{Y^{*}}\right)^{\beta_{2}}\left[F_{P}^{*}\left(Y^{*}\right)+\frac{c_{N}}{r}-\frac{Q_{N} Y^{*}}{r-\mu}\right] & \text { if } y>Y^{*} .\end{cases}
$$

The proof of this proposition can be found in "Appendix B".

Proposition 3 only makes economic sense if it is optimal to adopt STW before it is optimal to liquidate. This is - indeed - the case:

Corollary 1 Under the assumptions of Proposition 3 it holds that $Y^{*}>Y_{N}^{*}$.

The proof of this corollary is in "Appendix C".

In Fig. 1, the triggers $Y_{L}^{*}, Y_{H}^{*}$, and $Y^{*}$ are plotted for various values of cost reduction. It looks like the liquidation threshold is only marginally influenced by STW. We will see later, however, that the quantitative effect in terms of benefits of STW can be quite large.

\section{The effect of short-time work on liquidation probabilities}

In this section we compute the probabilities of liquidation of a representative firm over a certain period of time, based on data for several typical STW policies. In order to do so, we need more detail on the firm and how its production technology uses the production factors. Let's assume that the firm uses a fixed amount of capital, $K$, and a fixed amount of labour, $L$. 


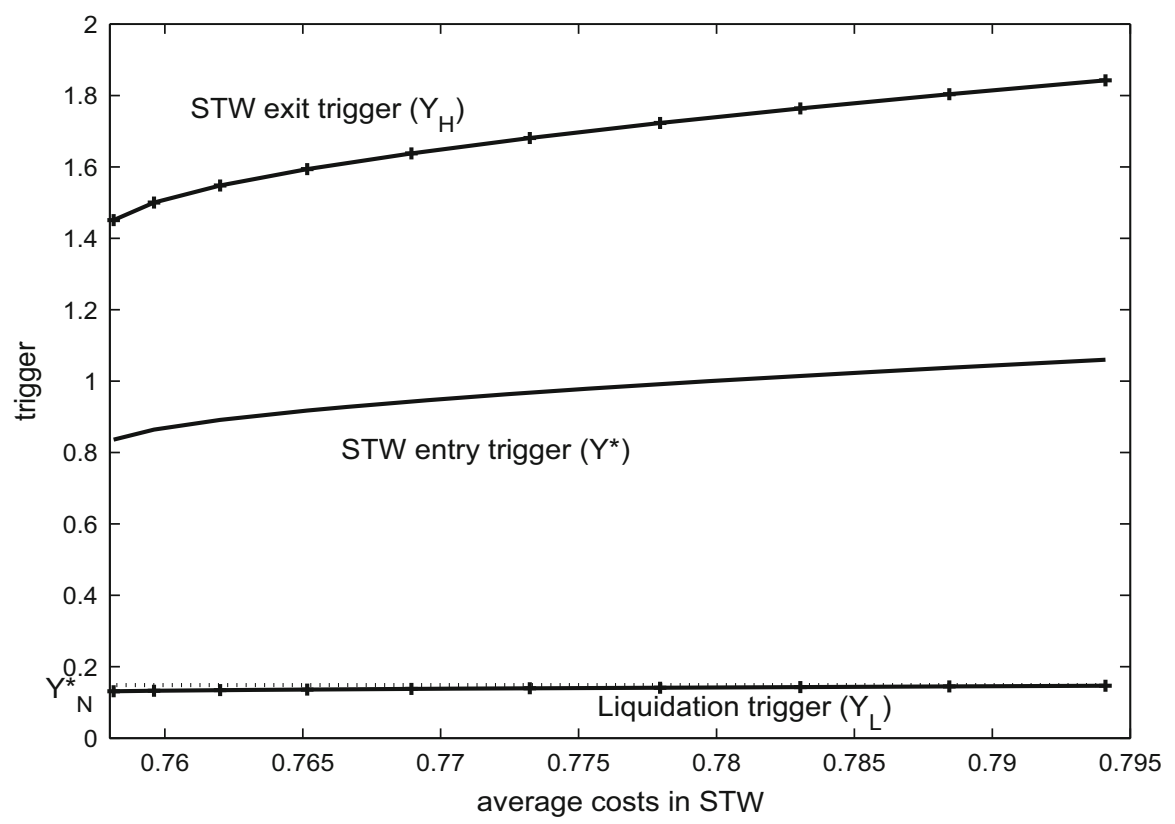

Fig. 1 Triggers for programme entry, programme exit, and default as a function of average production costs in STW. The base case parameters are $Q_{N}=10, c_{N}=8, r=0.04, \mu=0.03$, and $\sigma=0.15$. Note that in the base case the average costs of normal production are 0.8

The production function of the firm is assumed to be of the Cobb-Douglas type with constant returns to scale, i.e.

$$
Q_{N}=K^{1-\gamma} L^{\gamma}
$$

For simplicity, we assume that the rental rate of capital is constant and equal to $\rho$, and that the wage rate is constant at $w$. So, the flow paid to providers of capital (labour) is $\rho K$ $(w L)$. Therefore, $c_{N}=\rho K+w L$. For a given production level $Q_{N}$, the firm's (static) profit maximizing capital and labour inputs depend on the parameter $\gamma$. In particular,

$$
L=\left(\frac{\gamma}{1-\gamma} \frac{\rho}{w}\right)^{1-\gamma} Q_{N}, \text { and } K=\left(\frac{1-\gamma}{\gamma} \frac{w}{\rho}\right)^{\gamma} Q_{N} .
$$

Throughout this section we assume that $K$ and $L$ are chosen to maximize profits at production level $Q_{N}$.

A STW programme is characterized by a number of parameters. First, there is the fraction of worked hours that can be entered into STW, which we denote by $\alpha$. This implies that

$$
Q_{P}=K^{1-\gamma}[(1-\alpha) L]^{\gamma}=(1-\alpha)^{\gamma} Q_{N} .
$$

Secondly, the programme typically specifies the drop in the wage rate, which we denote by $1-\zeta$. So, for each non-worked hour the worker gets paid a fraction $\zeta$. Thirdly, the government usually only takes on a fraction $\eta$ of the wage rate (after the reduction has been implemented), leaving the firm to pay a fraction $1-\eta$. So, the cost flow of the firm drops to

$$
c_{P}=\rho K+(1-\alpha) w L+\alpha(1-\zeta)(1-\eta) w L=c_{N}-\alpha(\zeta+\eta-\zeta \eta) w L .
$$


Table 1 Two typical STW policies

Table 2 Base case parameter values

Table 3 Values related to the firm's production process

\begin{tabular}{llll}
\hline Policy & $\alpha$ & $\zeta$ & $\eta$ \\
\hline Nordic & 0.63 & 0.78 & 0.17 \\
Anglo-Saxon & 0.38 & 0.62 & 0.32 \\
\hline
\end{tabular}

\begin{tabular}{lllllll}
\hline Parameter & $r$ & $\mu$ & $\sigma$ & $\rho$ & $w$ & $Q_{N}$ \\
\hline Value & 0.04 & 0.02 & 0.25 & 0.06 & 0.06 & 10 \\
\hline
\end{tabular}

\begin{tabular}{llll}
\hline Variable & $\gamma$ & Nordic & Anglo-Saxon \\
\hline$K$ & 0.25 & 13.1607 & 13.1607 \\
& 0.50 & 10 & 10 \\
& 0.75 & 4.3869 & 4.3869 \\
& 0.25 & 4.3869 & 4.3869 \\
& 0.50 & 10 & 10 \\
$Q_{P}$ & 0.75 & 13.1607 & 13.1607 \\
& 0.25 & 7.7992 & 8.8736 \\
& 0.50 & 6.0828 & 7.8740 \\
$c_{N}$ & 0.75 & 4.7441 & 6.8970 \\
& 0.25 & 1.0529 & 1.0529 \\
& 0.50 & 1.2 & 1.2 \\
$c_{P}$ & 0.75 & 1.0529 & 1.0529 \\
& 0.25 & 0.9173 & 0.9787 \\
& 0.50 & 0.8910 & 1.0309 \\
& 0.75 & 0.6462 & 0.8303 \\
\hline
\end{tabular}

Cahuc and Carcillo [7] catalogue the wide variety of STW practices in OECD countries. These policies differ in virtually all relevant dimensions such as duration, maximum reduction in the number of hours worked $(\alpha)$, maximum reduction in salary paid $(1-\zeta)$ for non-worked hours, and maximum fraction of salaries paid by the government $(\eta)$. In order to analyse different real-world policies we group together the Nordic countries and the Anglo-Saxon countries and study the average policies in these groups. These data are all obtained from Cahuc and Carcillo [7]. See Table 1 for details. Note that the main difference between these policies is that the Nordic countries, typically, allow firms to cut into normal production levels more deeply, while permitting lower salary reductions.

We consider three types of firms where we differentiate between the labour intensity of the production process. In particular, we study the cases where $\gamma=0.25$ (relatively capital intensive), $\gamma=0.5$, and $\gamma=0.75$ (relatively labour intensive). The other parameters values are given in Table 2. Note that all the STW policies in Table 1 satisfy Assumptions 1-3 with these parameters.

For each firm we assume that $Q_{N}=10$. In Table 3 we record the normal costs of production $\left(c_{N}\right)$, the profit maximizing capital and labour input levels ( $K$ and $\left.L\right)$, and production level and costs in $\operatorname{STW}\left(Q_{P}\right.$ and $\left.c_{P}\right)$ under the different policies. 
Table 4 Triggers for various STW policies

\begin{tabular}{llll}
\hline Variable & $\gamma$ & Nordic & Anglo-Saxon \\
\hline$Y_{N}^{*}$ & 0.25 & 0.0259 & 0.0259 \\
& 0.50 & 0.0295 & 0.0295 \\
$Y^{*}$ & 0.75 & 0.0259 & 0.0259 \\
& 0.25 & 0.0455 & 0.0480 \\
& 0.50 & 0.0566 & 0.0572 \\
$Y_{L}^{*}$ & 0.75 & 0.0541 & 0.0524 \\
& 0.25 & 0.0250 & 0.0254 \\
& 0.50 & 0.0270 & 0.0282 \\
$Y_{H}^{*}$ & 0.75 & 0.0218 & 0.0240 \\
& 0.25 & 0.0887 & 0.0966 \\
& 0.50 & 0.0840 & 0.1190 \\
& 0.75 & 0.1206 & 0.1127
\end{tabular}

These typical policies lead to different thresholds and, thus, different probabilities of eventual liquidation. The thresholds are reported in Table 4.

Figure 2 shows a sample path for the process $\left(Y_{t}\right)_{t \geq 0}$, which illustrates the goal of STW policies. Here the current state of the economy is fairly low to start with and if no STW were available the firm would liquidate in about 1.8 years' time. With a Nordic style STW programme, the firm, along this particular sample path, would enter STW after approximately 0.2 years, where it remains for approximately 4.7 years. After that period it returns to normal production levels and, crucially, it is still productive after 5 years. Note that after about 2 years the firm almost liquidates, but the economy recovers in time to prevent liquidation from being the optimal choice.

In order to judge the efficacy of different STW policies, we compute the following probabilities:

1. that the firm liquidates within, say, $T$ years, and

2. that the firm uses the STW measure within $T$ years.

As long as $Y_{0} \equiv y>Y^{*}$, it can easily be derived from results for arithmetic Brownian motion as reported in, for example [12, Section 3.7], that these two probabilities are given by

$$
\begin{aligned}
\mathrm{P}_{y}\left(\inf _{0 \leq t \leq T} Y_{t} \leq Y_{N}^{*}\right)= & \Phi\left(\frac{\left.-\log \left(y / Y_{N}^{*}\right)+\left(.5 \sigma^{2}-\mu\right) T\right)}{\sigma \sqrt{T}}\right) \\
& +\exp \left\{\frac{\sigma^{2}-2 \mu}{\sigma^{2}} \log \left(\frac{y}{Y_{N}^{*}}\right)\right\} \Phi\left(\frac{\left.-\log \left(y / Y_{N}^{*}\right)-\left(.5 \sigma^{2}-\mu\right) T\right)}{\sigma \sqrt{T}}\right),
\end{aligned}
$$

and

$$
\begin{aligned}
\mathrm{P}_{y}\left(\inf _{0 \leq t \leq T} Y_{t} \leq Y^{*}\right)= & \Phi\left(\frac{\left.-\log \left(y / Y^{*}\right)+\left(.5 \sigma^{2}-\mu\right) T\right)}{\sigma \sqrt{T}}\right) \\
& +\exp \left\{\frac{\sigma^{2}-2 \mu}{\sigma^{2}} \log \left(\frac{y}{Y^{*}}\right)\right\} \Phi\left(\frac{\left.-\log \left(y / Y^{*}\right)-\left(.5 \sigma^{2}-\mu\right) T\right)}{\sigma \sqrt{T}}\right),
\end{aligned}
$$

respectively. Here $\Phi$ denotes the distribution function of the standard normal distribution. 


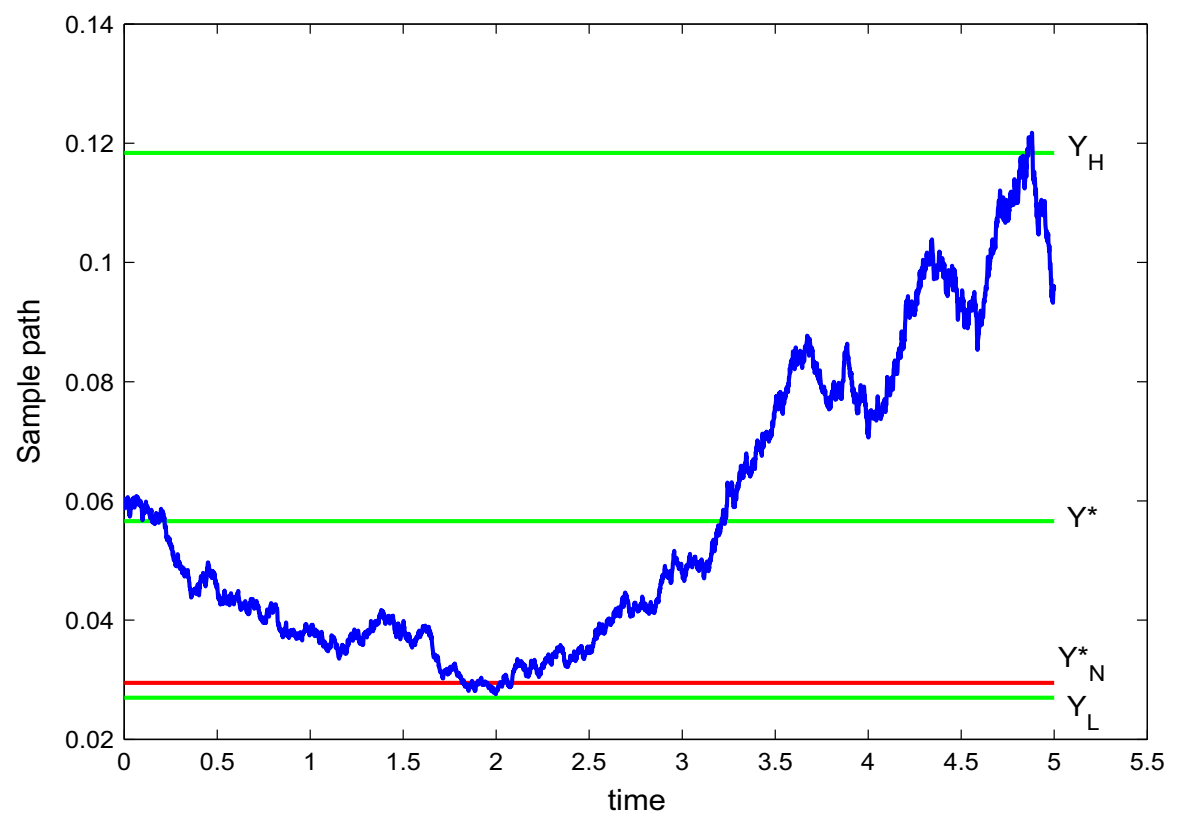

Fig. 2 A sample path for the process $\left(Y_{t}\right)_{t \geq 0}$ with triggers based on the base case firm scenario and a Nordicstyle STW policy

The probability of liquidation within $T$ years when the firm can use STW is very cumbersome to compute analytically, because of the multiple conditionalities involved. Recall that there are two possible liquidation scenarios:

1. the firm enters STW at $Y^{*}$ after which $Y_{L}^{*}$ is reached before $Y_{H}^{*}$, and

2. the firm enters STW at $Y^{*}$ after which $Y_{H}^{*}$ is reached before $Y_{L}^{*}$, and liquidation then takes place as soon as $Y_{N}^{*}$ is reached.

So, rather than pursuing analytical expressions for the liquidation probability in the presence of STW, we obtain estimates of this liquidation probability by simulating 50,000 sample paths.

For different values of $y$ and $T=5$ these liquidation probabilities are reported in Table 5 . The probabilities of entering STW are given in Table 6. As starting points we consider the initial states $1.5 Y_{N}^{*}$ (relatively weak economy), $2 Y_{N}^{*}$, and $3 Y_{N}^{*}$ (relatively benign economy), based on the threshold $Y_{N}^{*}$ for the case $\gamma=1 / 2$.

Note that under the Anglo-Saxon policy it is more likely that a firm enters the STW policy. However, under the Nordic policy the probability of firm liquidation is lower than under the Anglo-Saxon policy.

\section{Welfare effects of short-time work}

In this section we compare the total value of the firm and the total discounted stream of wages for workers under different STW scenarios. In order to do so, we need more detail on the firm and how its revenues are split between workers, capitalists and shareholders, for which we use the basic set-up used in Sect. 3. The surplus created by the firm (profit) is paid in full 
Table 5 Liquidation probabilities (exact without STW, simulated with STW) for various STW policies

\begin{tabular}{lllll}
\hline$\gamma$ & $y$ & No STW & Nordic & Anglo-Saxon \\
\hline 0.25 & 0.0442 & 0.3706 & 0.3374 & 0.3489 \\
& 0.0589 & 0.1624 & 0.1528 & 0.1520 \\
& 0.0884 & 0.0346 & 0.0288 & 0.0494 \\
0.50 & 0.0442 & 0.5026 & 0.4109 & 0.4481 \\
& 0.0589 & 0.2428 & 0.1866 & 0.2108 \\
& 0.0884 & 0.0600 & 0.0406 & 0.0494 \\
& 0.0442 & 0.3706 & 0.2288 & 0.2982 \\
& 0.0589 & 0.1624 & 0.0880 & 0.1245 \\
& 0.0884 & 0.0346 & 0.0152 & 0.0239 \\
\hline
\end{tabular}

\begin{tabular}{llll}
\hline$\gamma$ & $y$ & Nordic & Anglo-Saxon \\
\hline 0.25 & 0.0442 & 1 & 1 \\
& 0.0589 & 0.6718 & 0.7392 \\
0.50 & 0.0884 & 0.2630 & 0.3055 \\
& 0.0442 & 1 & 1 \\
0.75 & 0.0589 & 0.9488 & 0.9620 \\
& 0.0884 & 0.4594 & 0.4703 \\
& 0.0442 & 1 & 1 \\
& 0.0589 & 0.8922 & 0.8513 \\
& 0.0884 & 0.4144 & 0.3835
\end{tabular}

Table 6 Probabilities (exact) of entering STW for various STW policies to the firm's shareholders. The rental rate of capital, $\rho$, is, like the wage rate $w$, assumed to be exogenously given.

The welfare effects of STW depend crucially on the way payoffs related to possible future events (like entering STW, exiting STW and returning to normal production, etc.) are discounted. For a firm operating in STW, denote

$$
\begin{aligned}
& \hat{v}_{y}\left(Y_{L}^{*}, Y_{H}^{*}\right):=\mathrm{E}_{y}\left[e^{-r \hat{\tau}\left(Y_{H}^{*}\right)} \mid \hat{\tau}\left(Y_{H}^{*}\right)<\check{\tau}\left(Y_{L}^{*}\right)\right] \mathrm{P}_{y}\left(\hat{\tau}\left(Y_{H}^{*}\right)<\check{\tau}\left(Y_{L}^{*}\right)\right), \quad \text { and } \\
& \check{v}_{y}\left(Y_{L}^{*}, Y_{H}^{*}\right):=\mathrm{E}_{y}\left[e^{-r \check{\tau}\left(Y_{L}^{*}\right)} \mid \hat{\tau}\left(Y_{H}^{*}\right)>\check{\tau}\left(Y_{L}^{*}\right)\right] \mathrm{P}_{y}\left(\hat{\tau}\left(Y_{H}^{*}\right)>\check{\tau}\left(Y_{L}^{*}\right)\right) .
\end{aligned}
$$

In Proposition 2 we have already used the fact that (see, for example, [20, Section 5.9.1]):

$$
\begin{aligned}
& \hat{v}_{y}\left(Y_{L}^{*}, Y_{H}^{*}\right)=\frac{y^{\beta_{1}}\left(Y_{L}^{*}\right)^{\beta_{2}}-\left(Y_{L}^{*}\right)^{\beta_{1}} y^{\beta_{2}}}{\left(Y_{H}^{*}\right)^{\beta_{1}}\left(Y_{L}^{*}\right)^{\beta_{2}}-\left(Y_{L}^{*}\right)^{\beta_{1}}\left(Y_{H}^{*}\right)^{\beta_{2}}}, \text { and } \\
& \check{v}_{y}\left(Y_{L}^{*}, Y_{H}^{*}\right)=\frac{\left(Y_{H}^{*}\right)^{\beta_{1}} y^{\beta_{2}}-y^{\beta_{1}}\left(Y_{H}^{*}\right)^{\beta_{2}}}{\left(Y_{H}^{*}\right)^{\beta_{1}}\left(Y_{L}^{*}\right)^{\beta_{2}}-\left(Y_{L}^{*}\right)^{\beta_{1}}\left(Y_{H}^{*}\right)^{\beta_{2}}},
\end{aligned}
$$

where $\beta_{1}>1$ and $\beta_{2}<0$ are the solutions to the quadratic equation (2).

We assume that unemployment incurs a sunk cost equal to a fraction $\chi$ of discounted life-time earnings. It has been estimated [8] that $\chi=0.11$, increasing to $\chi=0.19$ in times of recession. Denoting the present value of expected payouts to capitalists, workers, and shareholders (all discounted at the same rate $r$ ) by $V_{k}, V_{\ell}$, and $V_{s}$, respectively, we find the following. 
Lemma 1 If the current value of the state-variable is $y$, then

$$
\begin{aligned}
& V_{k}(y)=\left[1-\left(\frac{y}{Y_{N}^{*}}\right)^{\beta_{2}}\right] \frac{\rho}{r} K, \\
& V_{\ell}(y)=\left[1-(1+\chi)\left(\frac{y}{Y_{N}^{*}}\right)^{\beta_{2}}\right] \frac{w}{r} L, \text { and } \\
& V_{s}(y)=\left[1-\left(\frac{y}{Y_{N}^{*}}\right)^{\beta_{2}}\right]\left[\frac{Q_{N} y}{r-\mu}-\frac{c_{N}}{r}\right] .
\end{aligned}
$$

We can now compute the value for each stakeholder (capitalist, worker, shareholder) under an STW programme.

Lemma 2 If the current value of the state-variable is $y$, then

$$
\begin{aligned}
V_{k}^{S T W}(y)= & {\left[1-\left(\frac{y}{Y_{N}^{*}}\right)^{\beta_{2}}\left(\hat{v}_{Y^{*}}\left(Y_{L}^{*}, Y_{H}^{*}\right)\left(\frac{Y_{H}^{*}}{Y_{N}^{*}}\right)^{\beta_{2}}+\check{v}_{Y^{*}}\left(Y_{L}^{*}, Y_{H}^{*}\right)\right)\right] \frac{\rho}{r} K, } \\
V_{\ell}^{S T W}(y)= & \left\{1+\left(\frac{y}{Y^{*}}\right)^{\beta_{2}}\left[-1+\left(1-\check{v}_{Y^{*}}\left(Y_{L}^{*}, Y_{H}^{*}\right)-\hat{v}_{Y^{*}}\left(Y_{L}^{*}, Y_{H}^{*}\right)\right)(1-\alpha(1-\zeta))\right.\right. \\
& \left.\left.+\hat{v}_{Y^{*}}\left(Y_{L}^{*}, Y_{H}^{*}\right)\left(1-\left(\frac{Y_{H}}{Y_{N}^{*}}\right)^{\beta_{2}}\right)-\chi\left(\check{v}_{Y^{*}}\left(Y_{L}^{*}, Y_{H}^{*}\right)+\hat{v}_{Y^{*}}\left(Y_{L}^{*}, Y_{H}^{*}\right)\left(\frac{Y_{H}^{*}}{Y_{N}^{*}}\right)\right)\right]\right\} \frac{w L}{r} \\
V_{S}^{S T W}(y)= & \left(1-\left(\frac{y}{Y^{*}}\right)^{\beta_{2}}\right)\left(\frac{Q_{N} y}{r-\mu}-\frac{c_{N}}{r}\right) \\
& +\left(\frac{y}{Y^{*}}\right)^{\beta_{2}}\left(1-\hat{v}_{Y^{*}}\left(Y_{L}^{*}, Y_{H}^{*}\right)-\check{v}_{Y^{*}}\left(Y_{L}^{*}, Y_{H}^{*}\right)\right)\left(\frac{Q_{P} y}{r-\mu}-\frac{c_{P}}{r}\right) \\
& +\left(\frac{y}{Y^{*}}\right)^{\beta_{2}} \hat{v}_{Y^{*}}\left(Y_{L}^{*}, Y_{H}^{*}\right)\left(1-\left(\frac{Y_{H}^{*}}{Y_{N}^{*}}\right)^{\beta_{2}}\right)\left(\frac{Q_{N} y}{r-\mu}-\frac{c_{N}}{r}\right) .
\end{aligned}
$$

The proof can be found in "Appendix E".

Typically, nordic STW programmes look more generous to workers in that they allow for a higher reduction in wage costs, lower reductions in salaries paid, and higher fractions of salaries paid for by the government. This would suggest that workers are better off in Nordic countries whereas shareholders are better off in Anglo-Saxon countries. The numerical analysis below shows that this intuition is incorrect.

The values to different stakeholders depend on the current price level in the market. Again we consider the initial states $1.5 Y_{N}^{*}, 2 Y_{N}^{*}$, and $3 Y_{N}^{*}$, based on the threshold $Y_{N}^{*}$ for the case $\gamma=1 / 2$. The values to each stakeholder of the different policies are reported in Tables 7, 8, 9 and 10 .

This numerical analysis indicates, firstly, that the biggest beneficiaries of STW are the capitalists. The benefit to workers is actually often negative. The intuition for this seeming paradox is simple: labour is the only production factor that is reduced in STW. By saving on wage costs the firm increases its life-span and, thus, the period of time during which the full rental costs of capital can be paid.

The occasional negative benefit to labour occurs because the decrease in the present value of sunk costs of unemployment is more than off-set by the decrease in the present value of the reduction in wages over the STW period. Note that the latter are discounted less than the former. 
Table 7 Value to capitalists (\% change relative to no STW in brackets)

\begin{tabular}{lllll}
\hline$\gamma$ & $y$ & No STW & Nordic & Anglo-Saxon \\
\hline 0.25 & 0.0442 & 7.9791 & $8.2935(3.94)$ & $8.1727(2.43)$ \\
& 0.0589 & 10.8319 & $11.0660(2.16)$ & $10.9724(1.30)$ \\
& 0.0884 & 13.7182 & $13.8765(1.15)$ & $13.8132(0.69)$ \\
0.50 & 0.0442 & 4.8595 & $5.6241(15.73)$ & $5.2603(8.25)$ \\
& 0.0589 & 7.3190 & $7.8465(7.21)$ & $7.5944(3.76)$ \\
& 0.0884 & 9.8074 & $10.1640(3.63)$ & $9.9936(1.90)$ \\
0.75 & 0.0442 & 2.6597 & $3.2068(20.57)$ & $2.9136(9.55)$ \\
& 0.0589 & 3.6106 & $3.9978(10.72)$ & $3.7907(4.99)$ \\
& 0.0884 & 4.5727 & $4.8344(5.72)$ & $4.6945(2.66)$ \\
\hline
\end{tabular}

\begin{tabular}{lllll}
\hline$\gamma$ & $y$ & No STW & Nordic & Anglo-Saxon \\
\hline 0.25 & 0.0442 & 2.2284 & $2.1561(-3.25)$ & $2.0901(-6.21)$ \\
& 0.0589 & 3.2840 & $3.2224(-1.88)$ & $3.1577(-3.84)$ \\
\multirow{2}{*}{0.50} & 0.0884 & 4.3519 & $4.3103(-0.96)$ & $4.2666(-1.96)$ \\
& 0.0442 & 3.7441 & $4.1049(9.64)$ & $3.7177(-0.70)$ \\
& 0.0589 & 6.4741 & $6.5215(0.73)$ & $6.2366(-3.67)$ \\
& 0.0884 & 9.2362 & $9.2683(0.35)$ & $9.0757(-1.74)$ \\
& 0.0442 & 6.6853 & $7.6319(14.16)$ & $6.7548(1.04)$ \\
& 0.0589 & 9.8519 & $10.2969(4.52)$ & $9.5610(-1.38)$ \\
& 0.0884 & 13.0557 & $13.3565(2.30)$ & $12.9637(-0.70)$ \\
\hline
\end{tabular}

Table 8 Value to workers, including sunk costs of unemployment $(\%$ change relative to no STW in brackets)

Table 9 Value to workers, excluding sunk costs of unemployment (\% change relative to no STW in brackets)

\begin{tabular}{lllll}
\hline$\gamma$ & $y$ & No STW & Nordic & Anglo-Saxon \\
\hline 0.25 & 0.0442 & 2.6597 & $2.5759(-3.15)$ & $2.5143(-5.47)$ \\
& 0.0589 & 3.6106 & $3.5405(-1.94)$ & $3.4793(-3.69)$ \\
& 0.0884 & 4.5727 & $4.5253(-1.04)$ & $4.4839(-1.94)$ \\
0.50 & 0.0442 & 4.8595 & $5.1363(5.69)$ & $4.7891(-1.45)$ \\
& 0.0589 & 7.3190 & $7.3084(-0.15)$ & $7.0512(-3.66)$ \\
& 0.0884 & 9.8074 & $9.8002(-0.07)$ & $9.6264(-1.85)$ \\
0.75 & 0.0442 & 7.9791 & $8.7452(9.60)$ & $7.9649(-0.18)$ \\
& 0.0589 & 10.8319 & $11.1492(2.93)$ & $10.6364(-1.80)$ \\
& 0.0884 & 13.7182 & $13.9327(1.56)$ & $13.5861(-0.96)$ \\
\hline
\end{tabular}

Secondly, the firm chooses its policy to maximize the value to shareholders, so it is no surprise that this value is positively affected by STW.

Next, all stakeholders are better off in the typical Nordic scenario than the typical AngloSaxon scenario. This suggest that more generous STW programmes do not necessarily hurt capitalists and shareholders. The reason for this might be that, even though firms under a Nordic policy pay more for non-worked hours, they are also allowed to reduce the number of hours worked more. 
Table 10 Value to shareholders (\% change relative to no STW in brackets)

\begin{tabular}{lllll}
\hline$\gamma$ & $y$ & No STW & Nordic & Anglo-Saxon \\
\hline 0.25 & 0.0442 & 3.7633 & $3.9231(4.25)$ & $3.8687(2.80)$ \\
& 0.0589 & 9.1969 & $9.3183(1.32)$ & $9.2785(0.89)$ \\
& 0.0884 & 21.9765 & $22.0586(0.37)$ & $22.0317(0.25)$ \\
0.50 & 0.0442 & 2.4242 & $2.9588(22.05)$ & $2.7068(11.66)$ \\
& 0.0589 & 7.2904 & $7.7709(6.59)$ & $7.5495(3.55)$ \\
& 0.0884 & 19.4959 & $19.8208(1.67)$ & $19.6711(0.90)$ \\
0.75 & 0.0442 & 3.7633 & $4.7392(25.93)$ & $4.2104(11.88)$ \\
& 0.0589 & 9.1967 & $10.0047(8.78)$ & $9.5610(3.96)$ \\
& 0.0884 & 21.9765 & $22.5226(2.48)$ & $22.2226(1.12)$ \\
\hline
\end{tabular}

As a final note, observe that since in the Cobb-Douglas technology capital and labour are interchangeable, an alternative to STW could be to negotiate a "pay holiday" between the firm and the capitalists. In such a scenario the roles between capital and labour would be reversed and it would be the workers who are more protected against a drop in the firm's value. Of course, a combination of the two approaches would share the losses more equally.

\section{Concluding remarks}

In this paper we studied a firm that can make use of a short-time work programme. Using a real options approach we derived the optimal thresholds for the firm to adopt STW and, once entered, when to exit and revert to normal production levels, or to liquidate. The liquidation threshold is computed both when the firm is using STW and when it is not. We show that a firm that is using STW will liquidate later than a firm that is not using it.

In practice, details of STW are highly variable between (OECD) countries. Our numerical computations are based on three different scenarios. One takes the STW details as they are common in Northern European countries. The second scenario looks at the way STW has been implemented typically in Anglo-Saxon countries. We take the point of view of a government and calculate the benefits to society of STW by a dynamic benefit-to-cost ratio and find that the dBCR is typically very small and far below unity. This happens because the benefits of STW accrue later in time than when the costs are incurred and are, thus, discounted more. This shows the importance of a stochastic dynamic approach to analysing such measures.

We also study the value of STW to different stakeholders in the firm. It turns out that workers are actually the worst off. STW is better for capitalists and shareholders. This happens because STW extends the life of the firm, so that capitalists get fully paid throughout that time while workers receive lower wages. Shareholders benefit through the option value that is generated by the presence of STW. We suggest that a "pay holiday" on capital goods payments could lead to similar results as STW but would protect the worker more. This suggests that a balanced approach may provide a better balance between costs and benefits of STW.

We list three possible extensions of this research. First, it would be interesting to make the duration that the firms can use STW time dependent. With such a model one could calculate the optimal duration of the programme both from a firm's and society perspective. Second, one could investigate what the effect would be from the possibility to make use of the programme more than once. Would firms adopt STW earlier? Would they exit earlier? 
Would this be beneficial for society? Third, it could be interesting to study the effect of STW in a competitive setting. How is the entry threshold of one firm affected by actions of other firms? What if a firm is in competition with another firm that is based in a country where STW measures do not exist? Finally, this paper has not addressed the effect of STW on the labour market. An important question to be asked is whether STW unfairly advantages workers employed in firms that have access to STW over workers who are not.

Open Access This article is licensed under a Creative Commons Attribution 4.0 International License, which permits use, sharing, adaptation, distribution and reproduction in any medium or format, as long as you give appropriate credit to the original author(s) and the source, provide a link to the Creative Commons licence, and indicate if changes were made. The images or other third party material in this article are included in the article's Creative Commons licence, unless indicated otherwise in a credit line to the material. If material is not included in the article's Creative Commons licence and your intended use is not permitted by statutory regulation or exceeds the permitted use, you will need to obtain permission directly from the copyright holder. To view a copy of this licence, visit http://creativecommons.org/licenses/by/4.0/.

\section{Appendix A: Proof of Proposition 2}

1. The optimal stopping problem (4) can be written as

$$
F_{P}^{*}(y)=\frac{Q_{P} y}{r-\mu}-\frac{c}{r}+\sup _{\tau} \mathrm{E}_{y}\left[e^{-r \tau} \max \left\{G_{L}\left(Y_{\tau}\right), G_{H}\left(Y_{\tau}\right)\right\}\right],
$$

where

$$
\begin{aligned}
& G_{L}(y)=-F_{P}(y)=\frac{c_{P}}{r}-\frac{Q_{P} y}{r-\mu}, \text { and } \\
& G_{H}(y)=F_{N}^{*}(y)-F_{P}(y)=\frac{Q_{N}-Q_{P}}{r-\mu} y-\frac{c_{N}-c_{P}}{r}+\left(\frac{y}{Y_{N}^{*}}\right)^{\beta_{2}}\left[\frac{c_{N}}{r}-\frac{Q_{N} Y_{N}^{*}}{r-\mu}\right] .
\end{aligned}
$$

Note that $G_{H}(y)>G_{L}(y)$ if, and only if, $y>Y_{N}^{*}$, and that $G_{H}\left(Y_{N}^{*}\right)=G_{L}\left(Y_{N}^{*}\right)$ and $G_{H}^{\prime}\left(Y_{N}^{*}\right)=G_{L}^{\prime}\left(Y_{N}^{*}\right)$. Hence, the gain function $y \mapsto \max \left\{G_{L}(y), G_{H}(y)\right\}$ is $C^{1}$ everywhere.

Define the function $G: \mathbb{R}_{+} \rightarrow \mathbb{R}$ by

$$
G(y)=1_{y \leq Y_{N}^{*}} G_{L}(y)+1_{y>Y_{N}^{*}} G_{H}(y),
$$

so that $G=G_{L} \vee G_{H}$. Note that $G$ is $C^{2}$ on $\mathbb{R}_{+} \backslash\left\{Y_{N}^{*}\right\}$.

2. From Peskir and Shiryaev [18] it follows that we need to find a set $\mathscr{C} \subset \mathbb{R}_{+}$and a function $F_{P}^{*} \in C^{2}\left(\mathbb{R}_{+} \backslash \partial \mathscr{C}\right)$, which dominates $G$ on $\mathbb{R}_{+}$, that solve the free-boundary problem

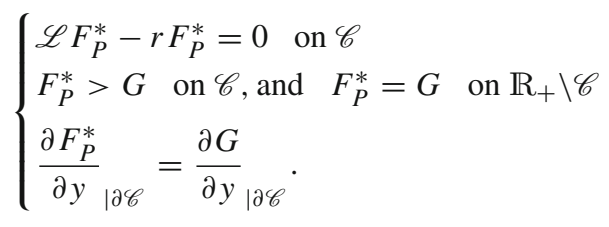

Here $\mathscr{L}$ denotes the characteristic operator of $\left(Y_{t}\right)_{t \geq 0}$, i.e., for any $\varphi \in C^{2}$,

$$
\mathscr{L} \varphi(y)=\frac{1}{2} \sigma^{2} y^{2} \varphi^{\prime \prime}(y)+\mu \varphi^{\prime}(y) .
$$

3. On $\mathbb{R}_{+}$, define the functions $\hat{\varphi}: \mathbb{R}_{+} \rightarrow \mathbb{R}_{+}$and $\check{\varphi}: \mathbb{R}_{+} \rightarrow \mathbb{R}_{+}$, by

$$
\hat{\varphi}(y)=y^{\beta_{1}}, \text { and } \check{\varphi}(y)=y^{\beta_{2}} .
$$


Note that $\hat{\varphi}$ and $\check{\varphi}$ are the increasing and decreasing solutions, respectively, to the differential equation $\mathscr{L} \varphi-r \varphi=0$. So, any solution to $\mathscr{L} \varphi-r \varphi=0$ is of the form

$$
\varphi(y)=\hat{A} \hat{\varphi}(y)+\check{A} \check{\varphi}(y),
$$

where $\hat{A}$ and $\check{A}$ are arbitrary constants. Furthermore, it is easily obtained that

$$
\begin{aligned}
& \hat{\varphi}^{\prime}(y)=\frac{\beta_{1}}{y} \hat{\varphi}(y)>0, \quad \check{\varphi}^{\prime}(y)=\frac{\beta_{2}}{y} \check{\varphi}(y)<0, \quad \text { and } \\
& \hat{\varphi}^{\prime \prime}(y)=\frac{\beta_{1}\left(\beta_{1}-1\right)}{y^{2}} \hat{\varphi}(y)>0, \quad \check{\varphi}^{\prime \prime}(y)=\frac{\beta_{2}\left(\beta_{2}-1\right)}{y^{2}} \check{\varphi}(y)>0 .
\end{aligned}
$$

4. Fix $Y_{L} \leq Y_{N}^{*}$ and define the mapping $y \mapsto V\left(y ; Y_{L}\right)$, by

$$
V\left(y ; Y_{L}\right)=\hat{A}\left(Y_{L}\right) \hat{\varphi}(y)+\check{A}\left(Y_{L}\right) \check{\varphi}(y),
$$

where the constants $\hat{A}\left(Y_{L}\right)$ and $\breve{A}\left(Y_{L}\right)$ are given by

$$
\hat{A}\left(Y_{L}\right)=\frac{\check{\varphi}\left(Y_{L}\right) G_{L}^{\prime}\left(Y_{L}\right)-\check{\varphi}^{\prime}\left(Y_{L}\right) G_{L}\left(Y_{L}\right)}{\check{\varphi}\left(Y_{L}\right) \hat{\varphi}^{\prime}\left(Y_{L}\right)-\check{\varphi}^{\prime}\left(Y_{L}\right) \hat{\varphi}\left(Y_{L}\right)}=\frac{\left(\beta_{2}-1\right) Q_{P} Y_{L} /(r-\mu)-\beta_{2} c_{P} / r}{\left(\beta_{1}-\beta_{2}\right) Y_{L}^{\beta_{1}}},
$$

and

$$
\check{A}\left(Y_{L}\right)=\frac{\hat{\varphi}^{\prime}\left(Y_{L}\right) G_{L}\left(Y_{L}\right)-\hat{\varphi}\left(Y_{L}\right) G_{I}^{\prime}\left(Y_{L}\right)}{\check{\varphi}\left(Y_{L}\right) \hat{\varphi}^{\prime}\left(Y_{L}\right)-\check{\varphi}^{\prime}\left(Y_{L}\right) \hat{\varphi}\left(Y_{L}\right)}=\frac{\left(1-\beta_{1}\right) Q_{P} Y_{L} /(r-\mu)+\beta_{1} c_{P} / r}{\left(\beta_{1}-\beta_{2}\right) Y_{L}^{\beta_{2}}} .
$$

Note that $\mathscr{L} V\left(y ; Y_{L}\right)-r V\left(y ; Y_{L}\right)=0$ for all $y \in \mathbb{R}_{+}$. In addition, the function $V$ satisfies $V\left(Y_{L} ; Y_{L}\right)=G_{L}\left(Y_{L}\right)$ and $V^{\prime}\left(Y_{L} ; Y_{L}\right)=G_{L}^{\prime}\left(Y_{L}\right)$.

It is easily seen that

$$
\check{A}\left(Y_{L}\right)>0 \text {, and } \check{A}^{\prime}\left(Y_{L}\right)>0 \text {. }
$$

In addition, Assumption 1 ensures that for all $Y_{L} \leq Y_{N}^{*}$, it holds that

$$
\hat{A}\left(Y_{L}\right)>0 \text {, and } \hat{A}^{\prime}\left(Y_{L}\right)<0 .
$$

5. So, the mapping $y \mapsto V\left(y ; Y_{N}^{*}\right)$ is a (strictly) convex function, which satisfies $V\left(\cdot ; Y_{N}^{*}\right) \rightarrow$ $\infty$ as $y \rightarrow \infty$ or $y \downarrow 0$. Hence, there is a unique point $\hat{Y}_{H}>Y_{N}^{*}$, such that $V^{\prime}\left(Y_{H} ; Y_{N}^{*}\right)=$ $G_{H}^{\prime}\left(Y_{H}\right)$. This is exactly the value $\hat{Y}_{H}$ determined by (7) in Assumption 2. This assumption then ensures that $V\left(Y_{H} ; Y_{N}^{*}\right)<G_{H}\left(Y_{H}\right)$. Also, since $V$ is more convex than $G_{H}$ for large $y$, it holds that $V\left(y ; Y_{N}^{*}\right)>G_{H}(y)$ for $y$ large enough.

6. Since $\hat{A}\left(Y_{L}\right)$ decreases and $\breve{A}\left(Y_{L}\right)$ increases in $Y_{L}$, the mapping $y \mapsto V\left(y ; Y_{L}\right)$ has the property that for every $y>Y_{L}$ it holds that $\partial V\left(y ; Y_{L}\right) / \partial Y_{L}<0$. So, the point $Y_{H} \in\left(Y_{N}^{*}, \infty\right)$ where $V^{\prime}\left(Y_{H} ; Y_{L}\right)=G_{H}^{\prime}\left(Y_{H}\right)$ is decreasing in $Y_{L}$, as is the value $V\left(Y_{H} ; Y_{L}\right)$. Now decrease $Y_{L}$ from $Y_{N}^{*}$ to 0 . There will be a unique $Y_{L}^{*}$, with corresponding $Y_{H}^{*}$ at which $V\left(Y_{H}^{*} ; Y_{L}^{*}\right)=$ $G_{H}\left(Y_{H}^{*}\right)$ and $V^{\prime}\left(Y_{H}^{*} ; Y_{L}^{*}\right)=G_{H}^{\prime}\left(Y_{H}^{*}\right)$.

7. The interval $\mathscr{C}=\left(Y_{L}^{*}, Y_{H}^{*}\right)$ and the proposed function $F_{P}^{*}=V\left(\cdot ; Y_{L}^{*}\right)$ together solve the free-boundary problem (13). The fact that $Y_{L}^{*}$ and $Y_{H}^{*}$ are the unique triggers that make $F_{P}^{*}$ a $C^{1}$ function on $\left(Y_{L}^{*}, Y_{H}^{*}\right)$ follows by construction.

\section{Appendix B: Proof of Proposition 3}

First note that for $y \in\left[Y_{L}^{*}, Y_{H}^{*}\right]$ we can write

$$
F_{P}^{*}(y)=F_{P}(y)+A y^{\beta_{1}}+B y^{\beta_{2}} .
$$


This implies that the first-order condition for maximizing $F^{*}(\cdot)$ can be written as $g(y)=0$, where

$$
\begin{aligned}
g(y) & =-\beta_{2}\left[F_{P}(y)-F_{N}(y)+A y^{\beta_{1}}+B y^{\beta_{2}}\right]+y\left[F_{P}^{\prime}(y)-F_{N}^{\prime}(y)+\beta_{1} A y^{\beta_{1}-1}+\beta_{2} B y^{\beta_{2}-1}\right] \\
& =-\beta_{2}\left[F_{P}(y)-F_{N}(y)\right]+y\left[F_{P}^{\prime}(y)-F_{N}^{\prime}(y)\right]+\left(\beta_{1}-\beta_{2}\right) A y^{\beta_{1}} .
\end{aligned}
$$

Since

$$
g^{\prime}(y)=\left(1-\beta_{2}\right) \frac{Q_{P}-Q_{N}}{r-\mu}+\beta_{1}\left(\beta_{1}-\beta_{2}\right) A y^{\beta_{1}-1},
$$

and

$$
g^{\prime \prime}(y)=\beta_{1}\left(\beta_{1}-1\right)\left(\beta_{1}-\beta_{2}\right) A y^{\beta_{1}-2}>0,
$$

$g(\cdot)$ is a strictly convex function, which can, therefore, have at most two zeros.

The minimum location of $g(\cdot)$ on $\left[Y_{L}^{*}, Y_{H}^{*}\right]$ can be found analytically:

$$
\begin{aligned}
g^{\prime}(y)=0 & \Longleftrightarrow y^{\beta_{1}-1}=\frac{1-\beta_{2}}{\beta_{1}\left(\beta_{1}-\beta_{2}\right) A} \frac{Q_{N}-Q_{P}}{r-\mu}=0 \\
& \Longleftrightarrow y=\left[\frac{1-\beta_{2}}{\beta_{1}\left(\beta_{1}-\beta_{2}\right) A} \frac{Q_{N}-Q_{P}}{r-\mu}\right]^{\frac{1}{\beta_{1}-1}} \equiv \check{Y} .
\end{aligned}
$$

We then find that

$$
\begin{aligned}
g(\check{Y}) & =\left(1-\beta_{2}\right) \frac{Q_{P}-Q_{N}}{r-\mu} \check{Y}+\left(\beta_{1}-\beta_{2}\right) A \check{Y}^{\beta_{1}}+\beta_{2} \frac{c_{P}-c_{N}}{r} \\
& =\check{Y}\left[\left(1-\beta_{2}\right) \frac{Q_{P}-Q_{N}}{r-\mu}+\left(\beta_{1}-\beta_{2}\right) A \check{Y}^{\beta_{1}-1}\right]+\beta_{2} \frac{c_{P}-c_{N}}{r} \\
& =\check{Y}\left[\left(1-\beta_{2}\right) \frac{Q_{P}-Q_{N}}{r-\mu}+\left(\beta_{1}-\beta_{2}\right) A \frac{1-\beta_{2}}{\beta_{1}\left(\beta_{1}-\beta_{2}\right) A} \frac{Q_{N}-Q_{P}}{r-\mu}\right]+\beta_{2} \frac{c_{P}-c_{N}}{r} \\
& =\check{Y} \frac{Q_{N}-Q_{P}}{r-\mu}\left(-\left(1-\beta_{2}\right)+\frac{1-\beta_{2}}{\beta_{1}}\right)+\beta_{2} \frac{c_{P}-c_{N}}{r} \\
& =\check{Y} \frac{Q_{N}-Q_{P}}{r-\mu} \frac{\left(1-\beta_{1}\right)\left(1-\beta_{2}\right)}{\beta_{1}}+\beta_{2} \frac{c_{P}-c_{N}}{r}<0,
\end{aligned}
$$

where the last inequality follows from Assumption 3.

Define

$$
f(y)=F_{P}(y)-F_{N}(y)+A y^{\beta_{1}}+B y^{\beta_{2}} .
$$

Since $A\left(Y_{H}^{*}\right)^{\beta_{1}}+B\left(Y_{H}^{*}\right)^{\beta_{2}}=F_{N}^{*}\left(Y_{H}^{*}\right)-F_{P}\left(Y_{H}^{*}\right)$, it holds that

$$
\begin{aligned}
f\left(Y_{H}^{*}\right) & =F_{P}\left(Y_{H}^{*}\right)-F_{N}\left(Y_{H}^{*}\right)+A\left(Y_{H}^{*}\right)^{\beta_{1}}+B\left(Y_{H}^{*}\right)^{\beta_{2}} \\
& =F_{N}^{*}\left(Y_{H}^{*}\right)-F_{N}\left(Y_{H}^{*}\right)=\left(\frac{Y_{H}^{*}}{Y_{N}^{*}}\right)^{\beta_{2}}\left[-F_{N}\left(Y_{N}^{*}\right)\right],
\end{aligned}
$$

and

$$
f^{\prime}\left(Y_{H}^{*}\right)=\beta_{2}\left(\frac{Y_{H}^{*}}{Y_{N}^{*}}\right)^{\beta_{2}} \frac{1}{Y_{H}^{*}}\left[-F_{N}\left(Y_{N}^{*}\right)\right] .
$$

We, therefore, find that 


$$
\begin{aligned}
g\left(Y_{H}^{*}\right) & =-\beta_{2} f\left(Y_{H}^{*}\right)+Y_{H}^{*} f^{\prime}\left(Y_{H}^{*}\right) \\
& =\left(1-\beta_{2}\right)\left(\frac{Y_{H}^{*}}{Y_{N}^{*}}\right)^{\beta_{2}}\left[-F_{N}\left(Y_{N}^{*}\right)\right]>0 .
\end{aligned}
$$

So, $g(\cdot)$ has a zero at $Y_{*} \in\left(\check{Y}, Y_{H}^{*}\right)$, which represents a minimum of $F^{*}(\cdot)$.

The function $F^{*}(\cdot)$ has a (unique) maximum at some $Y^{*} \in\left(Y_{L}^{*}, \check{Y}\right)$ if and only if $g\left(Y_{L}^{*}\right)>$ 0 . Note that

$$
\begin{aligned}
f\left(Y_{L}^{*}\right) & =F_{P}\left(Y_{L}^{*}\right)-F_{N}\left(Y_{L}^{*}\right)+A\left(Y_{L}^{*}\right)^{\beta_{1}}+B\left(Y_{L}^{*}\right)^{\beta_{2}} \\
& =F_{P}\left(Y_{L}^{*}\right)-F_{N}\left(Y_{L}^{*}\right)+\left[-F_{P}\left(Y_{L}^{*}\right)\right]=-F_{N}\left(Y_{L}^{*}\right),
\end{aligned}
$$

and

$$
f^{\prime}\left(Y_{L}^{*}\right)=-F_{N}^{\prime}\left(Y_{L}^{*}\right)
$$

which implies that

$$
g\left(Y_{L}^{*}\right)=-\beta_{2}\left[-F_{N}\left(Y_{L}^{*}\right)\right]+Y_{L}^{*}\left[-F_{N}^{\prime}\left(Y_{L}^{*}\right)\right]
$$

At $Y_{N}^{*}$ it holds that

$$
-\beta_{2}\left[-F_{N}\left(Y_{N}^{*}\right)\right]+Y_{N}^{*}\left[-F_{N}^{\prime}\left(Y_{N}^{*}\right)\right]=0,
$$

since $Y_{N}^{*}$ is a maximum location of $F_{N}^{*}(\cdot)$. It, therefore holds that $g\left(Y_{L}^{*}\right)>0 \Longleftrightarrow Y_{L}^{*}<Y_{N}^{*}$.

\section{Appendix C: Proof of Corollary 1}

Let

$$
Y_{P}^{*}=\frac{\beta_{2}}{\beta_{2}-1} \frac{r-\mu}{Q_{P}} \frac{c_{P}}{r} .
$$

That is, $\check{\tau}\left(Y_{P}^{*}\right)$ solves the optimal stopping problem

$$
G^{*}(y)=\sup _{\tau \in \mathscr{M}} \mathrm{E}_{y}\left[\int_{0}^{\tau} e^{-r t}\left(Y_{t} Q_{P}-c_{P}\right) d t\right] .
$$

Recall the function $g$ from the proof of Proposition 3. At $Y^{*}$ it holds that $g\left(Y^{*}\right)=0$, i.e. that

$$
\begin{aligned}
& \beta_{2}\left[F_{P}\left(Y^{*}\right)-F_{N}\left(Y^{*}\right)\right]=Y^{*}\left[F_{P}^{\prime}\left(Y^{*}\right)-F_{N}^{\prime}\left(Y^{*}\right)\right]+\left(\beta_{1}-\beta_{2}\right) A\left(Y^{*}\right)^{\beta_{1}} \\
& \Longleftrightarrow \beta_{2}\left[-F_{N}\left(Y^{*}\right)\right]-Y^{*}\left[-F_{N}^{\prime}\left(Y^{*}\right)\right] \\
& =-\left[-\beta_{2}\left(-F_{P}\left(Y^{*}\right)\right)+Y^{*}\left(-F_{P}^{\prime}\left(Y^{*}\right)\right)\right]+\left(\beta_{1}-\beta_{2}\right) A\left(Y^{*}\right)^{\beta_{1}} .
\end{aligned}
$$

Since at $Y_{P}^{*}$ it holds that

$$
-\beta_{2}\left[-F_{P}\left(Y_{P}^{*}\right)\right]+Y_{P}^{*}\left[-F_{P}^{\prime}\left(Y_{P}^{*}\right)\right]=0,
$$

$Y_{P}^{*}$ is a maximum location, and $Y^{*}>Y_{P}^{*}$, we have that the term between square brackets on the right-hand side of (18) is negative. Therefore, the right-hand side of (18) is positive.

This implies that

$$
-\beta_{2}\left[F_{P}\left(Y^{*}\right)+F_{N}\left(Y^{*}\right)\right]<0 .
$$

Since $Y_{N}^{*}$ solves

$$
-\beta_{2}\left[F_{P}\left(Y^{*}\right)+F_{N}\left(Y^{*}\right)\right]=0,
$$

and $Y_{N}^{*}$ is a maximum location it, therefore, holds that $Y^{*}>Y_{N}^{*}$. 


\section{Appendix D: Proof of Lemma 1}

For any $Y$ and $y<Y$, let $\hat{\tau}_{y}(Y)$ denote the first hitting time from below of $Y$ under $\mathrm{P}_{y}$. Similarly, for any $Y$ and $y>Y$, let $\check{\tau}_{y}(Y)$ denote the first hitting time from above of $Y$ under $\mathrm{P}_{y}$. For any $y>Y_{N}^{*}$, we then find that

$$
\begin{aligned}
V_{k}(y) & =\mathrm{E}_{y}\left[\int_{0}^{\check{\tau}_{y}\left(Y_{N}^{*}\right)} e^{-r t} \rho K d t\right] \\
& =\left(1-\mathrm{E}_{y}\left[e^{-r \check{\tau}_{y}\left(Y_{N}^{*}\right)}\right]\right) \mathrm{E}_{y}\left[\int_{0}^{\infty} e^{-r t} \rho K d t\right] \\
& =\left(1-\left(\frac{y}{Y_{N}^{*}}\right)^{\beta_{2}}\right) \frac{\rho}{r} K .
\end{aligned}
$$

The other values are computed in the same way, taking into account that the labour factor incurs a sunk cost equal to a fraction $\chi$ of life-time discounted expected labour income. That is, the sunk costs equal

$$
\chi \mathrm{E}_{y}\left[\int_{\check{\tau}_{y}\left(Y_{N}^{*}\right)}^{\infty} e^{-r t} w L d t\right]=\chi \mathrm{E}_{y}\left[e^{-r \check{\tau}_{y}\left(Y_{N}^{*}\right)}\right] \mathrm{E}_{y}\left[\int_{0}^{\infty} w L d t\right]=\chi\left(\frac{y}{Y_{N}^{*}}\right)^{\beta_{2}} \frac{w}{r} L .
$$

\section{Appendix E: Proof of Lemma 2}

The proof follows along similar lines as the proof of the previous lemma, i.e. by carefully discounting expected infinite streams of payoffs. Denote

$$
\begin{aligned}
& D K(y)=\mathrm{E}_{y}\left[\int_{0}^{\infty} e^{-r t} \rho K d t\right]=\frac{\rho}{r} K, \\
& D L_{N}(y)=\mathrm{E}_{y}\left[\int_{0}^{\infty} e^{-r t} w L d t\right]=\frac{w}{r} L, \\
& D L_{P}(y)=\mathrm{E}_{y}\left[\int_{0}^{\infty} e^{-r t}[(1-\alpha) w L+\alpha(1-\zeta) w L] d t\right]=\frac{1-\alpha \zeta}{r} w L, \\
& D S_{N}(y)=\mathrm{E}_{y}\left[\int_{0}^{\infty} e^{-r t}\left(Q_{N} Y_{t}-c_{N}\right) d t\right]=\frac{Q_{N} y}{r-\mu}-\frac{c_{N}}{r}, \quad \text { and } \\
& D S_{P}(y)=\mathrm{E}_{y}\left[\int_{0}^{\infty} e^{-r t}\left(Q_{P} Y_{t}-c_{P}\right) d t\right]=\frac{Q_{P} y}{r-\mu}-\frac{c_{P}}{r} .
\end{aligned}
$$

The providers of capital get paid a stream $\rho K$ until the firm liquidates. This happens either if the firms enters the STW programme and then hits the threshold $Y_{L}$, or if the firm enters the programme, then hits the threshold $Y_{H}$ and then hits the threshold $Y_{N}^{*}$. That is,

$$
\begin{aligned}
V_{k}^{S T W}(y)= & \mathrm{E}_{y}\left[\int_{0}^{\check{\tau}_{y}\left(Y^{*}\right)+\check{\tau}_{Y^{*}}\left(Y_{L}\right)} e^{-r t} \rho K d t \mid \check{\tau}_{Y^{*}}\left(Y_{L}\right)<\hat{\tau}_{Y^{*}}\left(Y_{H}\right)\right] \mathrm{P}_{Y^{*}}\left(\check{\tau}_{Y^{*}}\left(Y_{L}\right)<\hat{\tau}_{Y^{*}}\left(Y_{H}\right)\right) \\
& +\mathrm{E}_{y}\left[\int_{0}^{\check{\tau}_{y}\left(Y^{*}\right)+\hat{\tau}_{Y^{*}}\left(Y_{H}\right)+\check{\tau}_{Y^{*}}\left(Y_{N}^{*}\right)} e^{-r t} \rho K d t \mid \check{\tau}_{Y^{*}}\left(Y_{L}\right)>\hat{\tau}_{Y^{*}}\left(Y_{H}\right)\right]
\end{aligned}
$$




$$
\begin{aligned}
& \mathrm{P}_{Y^{*}}\left(\check{\tau}_{Y^{*}}\left(Y_{L}\right)>\hat{\tau}_{Y^{*}}\left(Y_{H}\right)\right) \\
= & \frac{\rho}{r} K\left\{1-\left(\frac{y}{Y^{*}}\right)^{\beta_{2}}\left[\check{v}_{Y^{*}}\left(Y_{L}, Y_{H}\right)+\hat{v}_{Y^{*}}\left(Y_{L}, Y_{H}\right)\left(\frac{Y_{H}}{Y_{N}^{*}}\right)^{\beta_{2}}\right]\right\} .
\end{aligned}
$$

The providers of labour receive a flow $w L$ while the firm operates normally and a flow $(1-\alpha+\alpha \zeta) w L=(1-\alpha \zeta) w L$ while the firm operates in STW. Therefore, assuming that $y>Y^{*}$, it holds that

$$
\begin{aligned}
V_{\ell}^{S T W}(y)= & \mathrm{E}_{y}\left[\int_{0}^{\hat{\tau}_{y}\left(Y^{*}\right)} e^{-r t} w L d t\right]+\mathrm{E}_{y}\left[\int_{\hat{\tau}_{y}\left(Y^{*}\right)}^{\hat{\tau}_{y}\left(Y^{*}\right)+\check{\tau}_{Y^{*}}\left(Y_{L}\right) \wedge \hat{\tau}_{Y^{*}}\left(Y_{H}\right)}(1-\alpha(1-\zeta)) w L d t\right] \\
& +\mathrm{E}_{y}\left[\int_{\hat{\tau}_{y}\left(Y^{*}\right)+\hat{\tau}_{Y^{*}}\left(Y_{H}\right)}^{\hat{\tau}_{y}\left(Y^{*}\right)+\hat{\tau}_{Y^{*}}\left(Y_{H}\right)+\check{\tau}_{Y} Y_{N}\left(Y_{N}^{*}\right)} e^{-r d t} w L d t \mid \hat{\tau}_{Y^{*}}\left(Y_{H}\right)<\check{\tau}_{Y^{*}}\left(Y_{L}\right)\right] \\
& \mathrm{P}_{Y^{*}}\left(\hat{\tau}_{Y^{*}}\left(Y_{H}\right)<\check{\tau}_{Y^{*}}\left(Y_{L}\right)\right) \\
& -\left\{\mathrm{E}_{y}\left[e^{-r\left(\hat{\tau}_{y}\left(Y^{*}\right)+\hat{\tau}_{Y^{*}}\left(Y_{H}\right)\right)} \mid \hat{\tau}_{Y^{*}}\left(Y_{H}\right)<\check{\tau}_{Y^{*}}\left(Y_{L}\right)\right] \mathrm{P}_{Y^{*}}\left(\hat{\tau}_{Y^{*}}\left(Y_{H}\right)<\check{\tau}_{Y^{*}}\left(Y_{L}\right)\right)\right. \\
& \left.+\mathrm{E}_{y}\left[e^{-r\left(\hat{\tau}_{y}\left(Y^{*}\right)+\check{\tau}_{Y^{*}}\left(Y_{L}\right)\right)} \mid \hat{\tau}_{Y^{*}}\left(Y_{H}\right)>\check{\tau}_{Y^{*}}\left(Y_{L}\right)\right] \mathrm{P}_{Y^{*}}\left(\hat{\tau}_{Y^{*}}\left(Y_{H}\right)>\check{\tau}_{Y^{*}}\left(Y_{L}\right)\right)\right\} \chi \frac{w L}{r} \\
= & \left(1-\left(\frac{y}{Y^{*}}\right)^{\beta_{2}}\right) \frac{w L}{r}+\left(\frac{y}{Y^{*}}\right)^{\beta_{2}}\left(1-\check{v}_{Y^{*}}\left(Y_{L}, Y_{H}\right)-\hat{v}_{Y^{*}}\left(Y_{L}, Y_{H}\right)\right)(1-\alpha(1-\zeta)) \frac{w L}{r} \\
& +\left(\frac{y}{Y^{*}}\right)^{\beta_{2}} \hat{v}_{Y^{*}}\left(Y_{L}, Y_{H}\right)\left(1-\left(\frac{Y_{H}}{Y_{N}^{*}}\right)^{\beta_{2}}\right) \frac{w L}{r} \\
& -\chi\left(\check{v}_{Y^{*}}\left(Y_{L}, Y_{H}\right)+\hat{v}_{Y^{*}}\left(Y_{L}, Y_{H}\right)\left(\frac{Y_{H}}{Y_{N}^{*}}\right)^{\beta_{2}}\right) \frac{w L}{r},
\end{aligned}
$$

from which the result follows immediately.

Finally, the value accruing to shareholders follows in a similar way and is already discussed in detail in Sect. 2.

\section{References}

1. Abel, A., Eberly, J.: A unified model of investment under uncertainty. Am. Econ. Rev. 84, 1369-1384 (1994)

2. Abraham, K., Houseman, S.: Does employment protection inhibit labor market flexibility? Lessons from Germany, France, and Belgium. In: Blank, R. (ed.) Social Protection versus Economic Flexibility, pp. 59-94. University of Chicago Press, Chicago (1995)

3. Bar-Ilan, A., Strange, W.: Investment lags. Am. Econ. Rev. 86, 610-622 (1996)

4. Bentolila, S., Cahuc, P., Dolado, J., Le Barbanchon, T.: Two-tier labour markets in the great recession: France versus Spain. Econ. J. 122, F155-F187 (2012)

5. Blanchard, O., Tirole, J.: The optimal design of unemployment insurance and unemployment protection: a first pass. J. Eur. Econ. Assoc. 6, 45-77 (2007)

6. Boeri, T., Bruecker, H.: Short-time work benefits revisited: some lessons from the great recession. Econ. Policy 26, 697-765 (2011)

7. Cahuc, P., Carcillo, S.: Is short-time work a good method to keep unemployment down? Nordic Econ. Policy Rev. 1, 133-165 (2011)

8. Davis, S., von Wachter, T.: Recessions and the cost of job loss. Brookings Papers on Economic Activity (2011, Sep)

9. Dixit, A.: Investment and employment dynamics in the short run and the long run. Oxf. Econ. Pap. 49, 1-20 (1997)

10. Dixit, A., Pindyck, R.: Investment Under Uncertainty. Princeton University Press, Princeton (1994)

11. Gryglewicz, S., Huisman, K., Kort, P.: Finite project life and uncertainty effects on investment. J. Econ. Dyn. Control 32, 2191-2213 (2008) 
12. Harrison, J.: Brownian Models of Performance and Control. Cambridge University Press, New York (2013)

13. Hijzen, A., Venn, D.: The role of short-time work schemes during the 2008-09 recession. Technical Report 115, OECD Social, Employment and Migration Working Papers (2011)

14. Kellogg, R.: The effect of uncertainty on investment: evidence from Texas oil drilling. Am. Econ. Rev. 104, 1698-1734 (2014)

15. Kolsrud, J., Landais, C., Nilsson, P., Spinnewijn, J.: The optimal timing of unemployment benefits: theory and evidence from sweden. Am. Econ. Rev. 108, 985-1033 (2018)

16. McDonald, R., Siegel, D.: The value of waiting to invest. Q. J. Econ. 101, 707-728 (1986)

17. Øksendal, B.: Stochastic Differential Equations, 5th edn. Springer, New York (2000)

18. Peskir, G., Shiryaev, A.: Optimal Stopping and Free-Boundary Problems. Birkhäuser Verlag, Basel (2006)

19. Rosen, S.: Implicit contracts: a survey. Journal of Economic Literature 23, 1144-1175 (1985)

20. Stokey, N.: The Economics of Inaction. Princeton University Press, Princeton (2009)

21. van Wijnbergen, S., Willems, T.: Imperfect information, lagged labour adjustment, and the great mmderation. Oxf. Econ. Pap. 65, 219-239 (2013)

Publisher's Note Springer Nature remains neutral with regard to jurisdictional claims in published maps and institutional affiliations. 